\title{
DRUG RESISTANCE IN GONORRHOEA WITH SPECIAL REFERENCE TO AETIOLOGY AND TREATMENT*
}

\author{
By A. H. HARKNESS, M.R.C.S., L.R.C.P. \\ Hon. Medical Officer in charge of Venereal Diseases Department, St. Peter's Hospital ; Consultant \\ in Venereal Diseases, St. Charles's Hospital (L.C.C.)
}

The body is well equipped to resist physical injury but in addition to such power there is that of tolerance or adaptation when the injury is repeated. As has been known for many years, the body may acquire an increased tolerance to certain drugs after frequent administration, good examples being those of the opium and arsenic eaters, who tolerate many times the dosage which would be fatal to normal individuals. Unicellular organisms (e.g., paramoecium) may also acquire a tolerance to normally lethal concentrations of various chemicals (Gay, 1935).

\section{Resistance of trypanosomes}

In 1907, two of Ehrlich's assistants (Franke and Roehl) observed that trypanosomes in nagana-infected mice which had survived the first effects of parafuchsin offered greater resistance to subsequent doses of the same drug (Ehrlich, 1907). The first feed of parafuchsin caused the disappearance of trypanosomes from the peripheral circulation but after a short period they reappeared. On further administration of the drug they again disappeared. The process was repeated several times but not indefinitely and eventually the drug did not have any action on the parasites, which had become drug-resistant or drug-fast. Subsequent investigations showed that strains of trypanosomes could be developed which were resistant to arsenic. Yorke (1933) states that on transference to normal mice the strains were still drug-fast. Drug-fast strains in mice may not be drug-fast when transferred to rats but Yorke maintains that a strain which is resistant in the mouse is also resistant when transferred to rat or rabbit. An observation similar to the above was made in spirochaetosis in fowls and mammals. Yorke, Murgatroyd and Hawking (1931) showed that normal strains of trypanosomes, in nutrient media containing known concentrations of reduced tryparsamide, rapidly absorb the drug (as shown by a diminished trypanocidal action of the fluid of the medium on fresh trypanosomes) whereas drug-fast strains fail to do so. Hawking (1937) corroborated the above by estimating the amount of arsenic in the medium and in the trypanosomes.

\section{Resistance of spirochaetes}

Akatsu and Noguchi (1917) were the first to show the development of drug fastness of spirochaetes (pallida, microdentium and refringens) to salvarsan, neosalvarsan, mercurial and iodide compounds in vitro, by subjecting them to gradually increased doses. The acquired resistance to the drugs in vitro gradually disappears on transference of the spirochaetes to drug-free media.

Armuzzi and Hoffmann (1927) state that strains of $S$. pallida recovered from arsphenamine-resistant patients were not resistant to the drug in animals. On the other hand, Beerman (1936) claims that there is correlation between resistant strains in men and rabbits ; the evidence put forward however is not convincing. Miller (quoted by Stokes, 1934) found that arsenic-resistant strains in mice were not resistant when transferred to rats but that they immediately regained their resistance on reinoculation in mice.

MacCormac (1935), Kloeppel (1926) and others have reported on couples infected with the same strains of $S$. pallida, and in each series both patients were resistant to arsenic and mercury. There are many more reports in the literature opposed to this view, the two most recent being those of Netherton (1943) and Templeton (1943). In summarizing the works of Jessner and Hoffmann (1923) Stokes (1934) considers that arsenic-resistant strains may exist although the clinically observed resistance is a peculiarity occurring in the host rather than in the organisms.

\footnotetext{
* An address given to the Medical Society for the Study of Venereal Diseases, October, 1943.
} 
Gonococci and resistance to sulphonamides

Dees and Colston in 1937 were the first to use sulphanilamide in the treatment of gonorrhoea, and since then both to this drug and to its many derivatives there have been numerous reports of drug resistance.

\section{Aetiology of drug resistance}

Drug resistance may be natural or acquired. It is interesting to note that Schmith and Reymann (1940) demonstrated in vitro the existence of natural drug resistance in an investigation of fifty strains of gonococci which had been isolated before the advent of chemotherapy. There are some organisms, for example Streptococcus faecalis, in which all strains show a marked natural resistance to these drugs. Joses (1942), in carrying out prophylactic treatment with sulphathiazole, reports that only one patient in a series of 450 cases developed gonorrhoea and was subsequently found to be resistant to all the sulphonamides ; this may be an example of natural resistance. Recent research seems to show that natural resistance to the sulphonamides may be due to the fact that the organisms are able to synthesize the essential metabolite, $p$-aminobenzoic acid. Acquired resistance may be due to (1) faulty dosage; (2) indiscretions of the patient ; (3) previous administration of the drug.

Faulty dosage.-There is laboratory and clinical evidence of the dangers of insufficient and irregular dosage, especially in the early stages of treatment. MacLean, Rogers and Fleming (1939) state that pneumococci in an infected animal treated with sulphapyridine readily establish a tolerance or fastness to the drug, and they consider it essential that the initial doses should be large.

Before proceeding any further it would perhaps be wise to state what I consider to be adequate dosage. I prescribe sulphathiazole or sulphadiazine, 4 grammes daily for five days, and if, before the commencement of treatment, there are symptoms of gross involvement of the posterior urethra I continue to give the drug for two additional days in a dosage of 3 grammes a day. Sulphapyridine is given for ten days, 4 grammes for one day, 3 grammes for six days and 2 grammes (1 gramme night and morning) for three days. Intensive therapy, especially with sulphapyridine, has, in my opinion, no place in the treatment of gonorrhoea.

Many patients seeking treatment for a persistent gonococcal discharge give the history of having taken only one tablet three or four times a day for short or long periods (usually due to the ignorance of the doctor). In others, however, adequate dosage has been prescribed and owing to toxic manifestations or forgetfulness the drug has not been taken regularly. In this way drug tolerance or drug fastness may be acquired and I cannot stress too strongly the importance of adequate and regular dosage, especially at the commencement of treatment, although undoubtedly a large percentage of the patients concerned do not develop resistance and react favourably on the institution of adequate dosage. Acquired tolerance to the less active sulphonamides such as sulphanilamide and sulphapyridine, as will be seen later, is often overcome by giving sulphathiazole and sulphadiazine. It must be remembered that some patients show natural drug resistance even after what I consider to be adequate dosage ; it also occurs when intensive therapy is used.

Indiscretions of the patient.-The taking of alcohol, and indulgence in sexual intercourse or excessive exercise are absolutely prohibited until the disease is cured, and when these precautions have been neglected, drug resistance may show itself.

Previous administration of the drug.-It is quite possible that drug tolerance may also be acquired during a previous administration of the drug with subeffective dosage for some other disease, and that it may also be a sequel to the local application of the drug. If this surmise is correct, large numbers of the population must be developing a tolerance to these powerful drugs, which are often prescribed in sub-effective dosage for trivial ailments. I have had several resistant cases in which the patients gave a previous history of having taken small doses of the sulphonamides weeks or months before contracting gonorrhoea, 
and I have also seen some cases which have occurred after the local application of the drug for the treatment of skin lesions.

\section{Degree of drug resistance}

In my opinion drug resistance may be either complete or partial and may follow either moderate or intensive therapy. When the resistance of the organism to the destructive effects of the sulphonamides is complete a profuse gonococcal discharge persists throughout the administration of the drug and there are no difficulties in diagnosing the condition. There is extension of the infective process, with gross glandular involvement. Anterior urethroscopy shows marked littritis and perilittritis and the prostate is always infected. Metastatic complications should now only occur in the drug-resistant cases. Urethrovesical irrigations do not control the discharge as they always did before the advent of chemotherapy, and it is my belief that the drug in these cases must interfere in some way with the normal defence mechanism of the body.

When the resistance of the organisms to the sulphonamides is partial it is a very easy matter for the condition to pass undiagnosed as the disease appears to be under control during the administration of the drug. The urine is invariably clear or contains only a few small threads in the first glass, but if urination is delayed for at least five hours a smear of the mucoid secretion at the external urinary meatus will reveal the presence of gonococci. There is without doubt a bacteriostatic effect, but the final knock-out blow to the disabled organisms by the leucocytes and reticulo-endothelial cells appears to be lacking. Soon after completion of the course of chemotherapy the organisms in most cases regain their vitality and there is usually an immediate gonococcal relapse ; but this may be delayed for a few weeks or even longer especially when local treatment is continued. I consider that this is the type of case which American workers refer to as " asymptomatic gonococcus carriers." The diagnosis can always be made during or on completion of the course of chemotherapy and it will be made easier if smears are taken before the first morning micturition. When this examination is carried out cultures are unnecessary. It is interesting to note that Cohn, Steer and Seijo (1942) found that organisms isolated from this type of case were susceptible in vitro.

\section{Incidence}

In a large series of my cases treated with sulphanilamide, sulphapyridine, sulphathiazole or sulphadiazine, the incidence of drug resistance when moderate dosage was used was $4 \cdot 1$ per cent. In their paper on intensive therapy King and Williams (1941) stated that the incidence among 397 patients, all of whom received 20 grammes of sulphapyridine in seventy-two hours, was 3.7 per cent ; but in my opinion it was higher, as fever therapy or urethral irrigations were necessary to effect a cure in a further sixty patients. Even with the use of the therapeutically more active sulphonamides, sulphathiazole and sulphadiazine, the incidence of drug resistance is increasing slightly instead of lessening. This may be due to an increase in the number of resistant strains, but in my opinion a large number of cases are due to a natural or acquired tolerance.

\section{Gonococcal fixation test}

The gonococcal fixation reaction on the blood serum does not afford any assistance in the diagnosis of this condition and in a large percentage of cases, especially when the resistance is partial, it remains negative. In complete drug resistance a positive reaction appears late in the disease and often after the stimulation of the defence mechanism either by the intravenous injection of a vaccine, by the intramuscular injection of a gonococcal vaccine or by protein shock produced by Aolan. It often persists for long periods and indeed a positive reaction is useless as a test for cure. I have noted in many of these cases, more so when the resistance is partial, that large numbers of the organisms are extracellular in position. 
Mechanism

The mechanism of drug resistance, provided that the drug is able to reach the infected lesions, is possibly explained by the success of the inhibitors ( $p$-aminobenzoic acid, peptones, and so on) in the competition for enzymes whose functioning is essential to the growth of the organisms. Stokinger, Charles and Carpenter (1942) found that experimentally developed sulphanilamide-resistant strains of gonococci produced increased amounts of $p$-aminobenzoic acid or related substances, but that the resistance of the organisms was not overcome by the addition of azochloramide, which inhibits $p$-aminobenzoic acid. They concluded that $p$-aminobenzoic acid was not responsible for the resistance in the gonococcus. Landy, Larkum, Oswald and Streightoff (1943) have confirmed these findings for $B$. coli, vibrio cholerae, dysentery bacilli and pneumococci, but have produced strong evidence in the case of $S$. aureus that resistance is due to changes in the metabolism of the organisms which lead to a marked increase in the synthesis of $p$-aminobenzoic acid. The recent recognition that $p$-aminobenzoic acid is a vitamin for man adds probability to the suggestion that the variable tissue concentration of this inhibitor to sulphonamide drugs may play a part in host factors.

\section{Causes of failure in therapy}

Failures in the treatment of gonorrhoea with one or more sulphonamide preparation may be due to (1) failure of the drug to reach the gonococci ; (2) resistance to the drug of the defence mechanism of the host (drug tolerance) ; (3) resistance to the drug of the gonococci (drug fastness). The generally accepted view is that failures in chemotherapy (provided the drug is able to reach the organisms), are invariably due to resistant strains. In my opinion too little attention is being given to the host factor which I consider is responsible for many of the failures.

Failure of the drug to reach the gonococci.-The host and the organisms may be blameless, and resistant infections may be due to failure of the drug to reach certain closed foci of infection or to non-absorption of the drug from the intestine. It is a well established clinical fact that the sulphonamides have little or no action on a peri-urethral abscess, an abscess of the prostate or an abscess of Cowper's gland, until the abscess bursts spontaneously or is drained. In gonococcal epididymitis there are multiple abscesses but they are small and the sulphonamides are able to reach them via the blood stream.

Blood estimations of free sulphonamides were carried out in twenty-five resistant and twenty-five susceptible cases and there were the same variations in both ( 2.5 to 7.5 milligrams per cent), proving that lack of absorption of the drug was not the cause of the failures. Estimations were carried out in Case 8 (see p. 14) during the administration of three of the four drugs which failed; the results are recorded in Table 1 , below.

TABLE 1

SULPHONAMIDE BLOOD CONCENTRATIONS

\begin{tabular}{lll|c|c}
\hline \multicolumn{2}{c|}{ DRUG } & & FREE & TOTAL \\
\hline Sulphamezathine & $\ldots$ & $\ldots$ & 5.07 & 7.06 \\
\hline Sulphapyridine & $\ldots$ & $\ldots$ & 2.5 & 3.19 \\
\hline Sulphathiazole & $\ldots$ & $\ldots$ & 5.55 & 5.8 \\
\hline
\end{tabular}

The above figures represent milligrams per cent
Fairbrother, Aymer and Ashton (1942) carried out blood estimations in six cases of gonorrhoea in which the patients did not respond to intensive chemotherapy, to ascertain whether absorption of the drug was incomplete and whether an effective blood level was obtained. Their investigations, too, indicated that the ineffectiveness of sulphapyridine in the refractory cases was not due to lack of absorption.

Resistance to the drug of the defence mechanisms of the host.-An investigation of couples who were considered to be infected with the same strain of gonococci gives strong evidence in favour of a host factor. In my series forty couples were infected with the same strain of organisms. In two instances one or the other of the parties was resistant to treatment but only twice were both resistant. 
On one occasion three men were infected by the same woman. Two of the contacts were cured by a five-day course of sulphathiazole ; one was resistant to sulphathiazole, sulphapyridine and sulphadiazine ; fever therapy was necessary to effect a cure. At my request Mascall (1943) investigated forty-seven couples attending the Whitechapel Clinic for treatment and found that six males and five females were resistant to one or more of these drugs but on no occasion were both contacts resistant to treatment.

Resistance to the drug of the gonococci.-Felke (1938), Levaditi and Vaisman (1938) and Herrold (1938) reported the occurrence of strains of gonococci resistant to sulphanilamide. Boak, Charles and Carpenter (1939) proved that the gonococcus acquired tolerance to sulphanilamide when progressively increasing amounts of the drug were added to the culture media and that a higher concentration of the drug could be tolerated by the organisms in vitro than could be maintained in the blood of man. Westphal, Charles and Carpenter (1940) obtained identical results with sulphapyridine in nine out of ten strains of gonococci. The experiments were carried out after MacLean, Rogers and Fleming had reported the development in vitro of sulphapyridine-fast strains of pneumococci. Westphal, Charles and Carpenter also stated that sulphapyridine fastness persisted for at least two months when the organisms were subcultured in media free from sulphapyridine. Sulphapyridine-fast strains of gonococci grew. equally well in the higher concentrations of sulphanilamide, but sulphanilamide-fast strains grew only in the lower concentrations of sulphapyridine.

Felke (1939) tested 140 strains of gonococci for sulphanilamide resistance in culture, and the results obtained suggested the acquisition of sulphanilamide resistance in vitro. Wezel (1938) found that gonococci from patients who had been resistant to Diseptal $C$ would not grow on media containing 1.0 milligram per cent of the same drug.

In 1938 Cohn stated that strains of gonococci from patients whose infections were resistant to sulphanilamide showed no resistance in culture. Cohn, Steer and Seijo state that strains of gonococci which are resistant to treatment with sulphathiazole are also resistant in vitro ; four strains out of thirty-four lacked clinical and laboratory correlation. Of these, one from a patient who was resistant to treatment was susceptible in vitro and another from a patient who reacted to treatment was resistant in vitro. The other two strains were obtained from the two patients who were suffering from what I term partial drug resistance (so-called gonococcus carriers) and both were susceptible in vitro.

Satterthwaite, Hill and Huffer (1942) tested in vitro two clinically resistant strains of gonococci. One was found to be resistant to sulphanilamide, sulphathiazole and sulphadiazine and the other to sulphanilamide only. Petro (1943) in an investigation of forty-four cases of gonorrhoea, six of which were resistant to treatment, states that resistant strains of organisms were responsible for the failures.

\section{Results of personal investigations}

It will be seen from the above that a large majority of laboratory workers consider that strains of gonococci which have been isolated from resistant cases are also resistant in vitro. My first investigation led me to a different conclusion. In this series, in March, 1942, the organisms cultured from five resistant cases were tested in vitro against sulphanilamide, sulphathiazole, sulphabenzamide, sulphadiazine, sulphapyridine, 4-4' diaminodiphenylsulphone and 4-4' bis (a $\beta$-phenyl-N-propylamino) diphenyl-sulphone tetrasodium sulphonate.

The drugs were used in a concentration of 1 in 500 in a nutrient broth containing 10 per cent of serum except in the case of sulphadiazine and 4-4' diaminodiphenylsulphone which were not soluble to that extent and were used in a concentration of 1 in 1,000 . The organisms were inoculated from a forty-eight hour blood agar slope, the approximate numbers per cubic centimetre in the drug broths being 2.5 millions falling in 10 per cent steps (i.e., each tube containing 10 per cent of the number of organisms in the next highest) to $2 \cdot 5$. All the drugs completely 
DRUG RESISTANCE IN GONORRHOEA

TABLE 2.-RESISTAN I STRAINS

Strains resistant in Host

STRAIN

DRUGS

\begin{tabular}{|c|c|c|c|c|}
\hline & $\mathbf{S}$ & ST & SD & SP \\
\hline$(\mathrm{S}, \mathrm{SP})$ & $\begin{array}{l}1 / 625 \\
(0 \cdot 16)\end{array}$ & $\begin{array}{l}1 / 10,000 \\
(0.01)\end{array}$ & $\begin{array}{l}1 / 5,000 \\
(0 \cdot 02)\end{array}$ & $\begin{array}{l}1 / 2,500 \\
(0 \cdot 04)\end{array}$ \\
\hline$(\mathrm{S}, \mathrm{SP}, \mathrm{ST})$ & $\begin{array}{l}1 / 2,500 \\
(0.04)\end{array}$ & $\begin{array}{l}1 / 10,000 \\
(0.01)\end{array}$ & $\begin{array}{l}1 / 2,500 \\
(0 \cdot 04)\end{array}$ & $\begin{array}{l}1 / 1,250 \\
(0.08)\end{array}$ \\
\hline$(\mathrm{S}, \mathrm{3} \mathrm{SP})$ & $\begin{array}{c}1 / 5,000 \\
(0.02)\end{array}$ & $\begin{array}{l}<1 / 160,000 \\
(0.00062)\end{array}$ & $\begin{array}{l}1 / 80,000 \\
(0.00125)\end{array}$ & $\begin{array}{l}1 / 40,000 \\
(0.0025)\end{array}$ \\
\hline $\begin{array}{l}4 \\
\text { (S, S and methy- } \\
\text { lene blue) }\end{array}$ & $\begin{array}{c}1 / 5,000 \\
(0.02)\end{array}$ & $\begin{array}{l}1 / 2,500 \\
(0.04)\end{array}$ & $\begin{array}{l}1 / 625 \\
(0 \cdot 16)\end{array}$ & $\begin{array}{c}>1 / 312 \cdot 5 \\
(0.32\end{array}$ \\
\hline$(\mathrm{S}, \mathrm{S} \stackrel{\mathrm{P}}{\mathrm{P}}, \mathrm{ST})$ & - & $\begin{array}{l}1 / 20,000 \\
(0 \cdot 005)\end{array}$ & $\begin{array}{l}1 / 10,000 \\
(0 \cdot 01)\end{array}$ & $\begin{array}{l}1 / 2,500 \\
(0.04)\end{array}$ \\
\hline$\left(\mathrm{S}, \mathrm{SP}, \mathrm{ST}^{6}, \mathrm{SD}, \mathrm{SM}\right)$ & $\begin{array}{c}1 / 20,000 \\
(0.005)\end{array}$ & $\begin{array}{l}<1 / 160,000 \\
(0.00062)\end{array}$ & $\begin{array}{c}<1 / 160,000 \\
(0.00062)\end{array}$ & $\begin{array}{l}1 / 20,000 \\
(0.005)\end{array}$ \\
\hline $\begin{array}{c}7 \\
(\mathrm{~S})\end{array}$ & $\begin{array}{l}1 / 20,000 \\
(0 \cdot 005)\end{array}$ & $\begin{array}{c}1 / 10.24 \times 10^{6} \\
(0.0000098)\end{array}$ & $\begin{array}{c}1 / 640,000 \\
(0.000158)\end{array}$ & $\begin{array}{c}1 / 1.28 \times 10^{6} \\
(0.000078)\end{array}$ \\
\hline$(\mathrm{SM}, \underset{8 \mathrm{SP}, \mathrm{ST}, \mathrm{SD})}{\mathrm{S}(1)}$ & $\begin{array}{l}1 / 2,500 \\
(0 \cdot 04) \\
1 / 625 \\
(0 \cdot 16)\end{array}$ & $\begin{array}{c}1 / 20,000 \\
(0.005) \\
-\end{array}$ & $\begin{array}{c}1 / 10,000 \\
(0 \cdot 01) \\
1 / 625 \\
(0 \cdot 16)\end{array}$ & $\begin{array}{l}1 / 2,500 \\
(0 \cdot 04) \\
1 / 312 \cdot 5 \\
(0 \cdot 32)\end{array}$ \\
\hline$\stackrel{9}{(\mathbf{S})}$ & $\begin{array}{l}1 / 10,000 \\
(0.01)\end{array}$ & $\begin{array}{l}<1 \cdot 160,000 \\
(0.00062)\end{array}$ & $\begin{array}{l}1.40,000 \\
(0.0025)\end{array}$ & $\begin{array}{c}1 / 10,000 \\
(0.01)\end{array}$ \\
\hline$(\mathrm{SD}, \stackrel{10}{\mathrm{SP}}, \mathrm{S})$ & $\begin{array}{c}>1 / 312.5 \\
(0.32)\end{array}$ & $\begin{array}{l}1 / 625 \\
(0 \cdot 16)\end{array}$ & $\begin{array}{c}>1 / 312 \cdot 5 \\
(0.32)\end{array}$ & $\begin{array}{c}>1 / 312.5 \\
(0.32)\end{array}$ \\
\hline $\begin{array}{c}11 \\
(\mathrm{~S})\end{array}$ & $\begin{array}{c}1 / 10,0000 \\
(0 \cdot 01)\end{array}$ & $\begin{array}{c}1 / 2.56 \times 10^{6} \\
(0.0000390)\end{array}$ & $\begin{array}{c}1 / 80,000 \\
(0.00125)\end{array}$ & $\begin{array}{c}1 / 80,000 \\
(0.00125) \\
\end{array}$ \\
\hline$(\mathrm{S}, \mathrm{SP})$ & $\begin{array}{l}1 / 1,250 \\
(0 \cdot 08)\end{array}$ & $\begin{array}{l}1 / 40,000 \\
(0.0025)\end{array}$ & $\begin{array}{l}1 / 10,000 \\
(0.01)\end{array}$ & $\begin{array}{l}1 / 2,500 \\
(0.04)\end{array}$ \\
\hline $\begin{array}{l}13 \\
(\mathrm{SP})\end{array}$ & $\begin{array}{l}1 / 5,000 \\
(0.02)\end{array}$ & $\begin{array}{l}1 / 40,000 \\
(0 \cdot 0025)\end{array}$ & $\begin{array}{c}1 / 20,000 \\
(0.005)\end{array}$ & $\begin{array}{l}1 / 5,000 \\
(0.027)\end{array}$ \\
\hline $\begin{array}{c}14 \\
(\mathrm{SP})\end{array}$ & $\begin{array}{c}1 / 2,500 \\
(0 \cdot 04)\end{array}$ & $\begin{array}{c}1 / 80,000 \\
(0.00125)\end{array}$ & $\begin{array}{l}1 / 20,000 \\
(0.005)\end{array}$ & $\begin{array}{c}1 / 20,000 \\
(0 \cdot 005)\end{array}$ \\
\hline $\begin{array}{l}15 \\
(S)\end{array}$ & $\begin{array}{c}1 / 2,500 \\
(0 \cdot 04)\end{array}$ & $\begin{array}{c}1 / 10,000 \\
(0.01)\end{array}$ & $\begin{array}{c}1 / 2,500 \\
(0.04)\end{array}$ & $\begin{array}{c}1 / 5,000 \\
(0.02) \\
\end{array}$ \\
\hline$(\mathrm{ST}, \mathrm{SD})$ & $\begin{array}{c}1 / 5,000 \\
(0.02)\end{array}$ & $\begin{array}{c}1 / 80,000 \\
(0.00125) \\
\end{array}$ & $\begin{array}{c}1 / 80,000 \\
(0.00125)\end{array}$ & $\begin{array}{l}1 / 160,000 \\
(0.00062)\end{array}$ \\
\hline$(\mathrm{SP}, \mathrm{ST})$ & $\begin{array}{c}1 / 2,500 \\
(0.04)\end{array}$ & $\begin{array}{l}1 / 40,000 \\
(0.0025)\end{array}$ & $\begin{array}{c}1 / 10,000 \\
(0.01)\end{array}$ & $\begin{array}{l}1 / 5,000 \\
(0.02)\end{array}$ \\
\hline $\begin{array}{l}18(1) \\
(\mathrm{ST}, \mathrm{SD}) \\
18(2)\end{array}$ & $\begin{array}{l}1 / 20,000 \\
(0.005) \\
1 / 10,000 \\
(0.01)\end{array}$ & $\begin{array}{l}(1 \cdot 80,000) \\
(0.00125) \\
1 / 40,000 \\
(0.0025)\end{array}$ & $\begin{array}{c}1 / 40,000 \\
(0 \cdot 0025) \\
1 / 20,000 \\
(0 \cdot 005)\end{array}$ & $\begin{array}{l}1 / 40,000 \\
(0.0025) \\
1 / 40,000 \\
(0.0025)\end{array}$ \\
\hline$(\mathrm{ST}, \mathrm{19} \mathrm{SD}, \mathrm{SM})$ & $\begin{array}{l}1 / 10,000 \\
(0 \cdot 01)\end{array}$ & $\begin{array}{c}1 / 20,000 \\
(0.005)\end{array}$ & $\begin{array}{l}1 / 5,000 \\
(0.02)\end{array}$ & $\begin{array}{l}1 / 40,000 \\
(0.0025)\end{array}$ \\
\hline (ST, $\stackrel{20}{\mathrm{SD}, \mathrm{SP})}$ & $\begin{array}{l}1 / 160,000 \\
(0.00062)\end{array}$ & $\begin{array}{l}1 / 5.12 \times 10^{6} \\
(0.0000195)\end{array}$ & $\begin{array}{l}1 / 2.56 \times 10^{6} \\
(0.0000390)\end{array}$ & $\begin{array}{c}1 / 640,000 \\
(0.000155)\end{array}$ \\
\hline$(\mathrm{SP}, \mathrm{ST}, \mathrm{SD}, \mathrm{SM})$ & $\begin{array}{c}1 / 20,000 \\
(0.005)\end{array}$ & $\begin{array}{l}1 / 320,000 \\
(0.00031)\end{array}$ & $\begin{array}{l}1 / 160,000 \\
(0.00062)\end{array}$ & $\begin{array}{c}1 / 80,000 \\
(0.00125)\end{array}$ \\
\hline
\end{tabular}

$\mathbf{S}=$ Sulphanilamide. $\quad \mathbf{S T}=$ Sulphathiazole. $. \quad \mathbf{S D}=$ Sulphadiazine $\quad \mathbf{S P}=$ Sulphapyridine. $\mathbf{S M}=$ Sulphamezathine.

Drugs, printed in brackets, under the resistant strains are those to which the strain had proved resistant in the host. Figures given under each drug are the minimal inhibitory concentrations for the corresponding strain. Figures in brackets under the minimal inhibitory concentrations are the corresponding percentages (grammes per 100 cubic centimetres of broth). When the symbol $>$ or $<$ is used it indicates that no end point was reached in the range put up. End points would be obtained by repeating the test, using a different range. Two separate tests were carried out on strains 8 and 18 , cultures having been obtained (1) before the commencement of treatment and (2) after failure with two drugs. 
inhibited the growth of organisms, while satisfactory growth occurred in the control tubes after incubation at $37^{\circ} \mathrm{C}$. for forty-eight hours. Incubation was continued for six days, after which time there was still no growth in the drug broths.

In addition, blood agar plates incorporating the drugs in concentrations of 1 in 500,1 in $1,000,1$ in 2,000, 1 in 4,000 (sulphadiazine and diaminodiphenylsulphone 1 in $1,000,1$ in $2,000,1$ in $4,000,1$ in 8,000) were made, and $0 \cdot 1$ cubic centimetre of a suspension of organisms from a forty-eight-hour blood agar slope spread on the surface. After incubation for forty-eight hours at $37^{\circ} \mathrm{C}$. satisfactory growth had occurred on the control plates, while all the other plates, except that containing the diaminodiphenylsulphone medium, were negative. In the case of the diaminodiphenylsulphone plates, on which growths had occurred, it was found that the drug had crystallized out in the medium.

It will be seen that all these strains of gonococci which were resistant in the host were susceptible in vitro, but it is admitted that the concentrations used, except for sulphanilamide, were too high. The laboratory work was repeated on strains of gonococci cultivated from twenty-one resistant and twelve susceptible cases, but at my request lower concentrations of the drugs were used and the results (Tables 2 and 3 ) are based on at least three separate tests on each strain.

All cultures were dried by W. H. Proom's method, the details of which are as follows.

(1) The overnight growths on two slopes of suitable medium are emulsified in about 2 cubic centimetres of Wright's broth and divided out into sterile plugged Lambeth tubes, two or three drops in each.

(2) Four hundred grammes of powdered carbon dioxide ice are placed in a metal box (with lid) which in turn is placed in an insulated box.

(3) Seven hundred and fifty grammes of powdered carbon dioxide ice are added to a desiccator containing a layer of glycerin one inch deep, and the tubes of culture are partly submerged in the mixture.

(4) A tripod supporting a large Petri dish containing phosphoric oxide is placed in the desiccator.

(5) The lid of the desiccator is connected with a Rivac pump which is switched on. Then the lid is firmly pressed on to the desiccator and the whole placed in the insulated box.

(6) Next morning the top of the desiccator is closed, disconnected from the pump and placed on the bench for about two hours to bring it up to room temperature.

(7) Dry nitrogen is run into the desiccator.

(8) The plugs in the culture tubes are pushed in and the tubes sealed off in a flame. These tubes are labelled and then tested for viability and purity.

Before testing, one of the dried cultures of each strain is taken up in a little Wright's broth, inoculated on to a slope of suitable medium and incubated.

Tests were carried out on all strains before and after drying and the results were the same. The process of drying overcomes the well-known difficulty of maintaining strains at the virulence of isolation. Previous experiments on other organisms had proved that their virulence was unaltered by the process. The strains were grown on blood agar slopes for twenty-four or forty-eight hours at $37^{\circ} \mathrm{C}$. A suspension of this growth in broth was used as an inoculum. Counts made on blood agar plates showed that the actual number of organisms inoculated into the drug broths varied between $30 \times 10^{6}$ and $400 \times 10^{6}$ giving a final count in the drug broths of $6 \times 10^{6}$ to $40 \times 10^{6}$.

The drugs were dissolved in Wright's broth and autoclaved in bulk. After autoclaving, serum was added to the starting solution in a concentration of 10 per cent. The starting solution was then pipetted through a series of 5 cubic centimetre quantities of Wright's broth +10 per cent serum to make a series of graded dilutions. These graded series were then inoculated with 0.1 cubic centimetre of the suspension of organisms, and incubated at $37^{\circ} \mathrm{C}$. After three days the tests were read, and subcultures made, from the tubes showing no visible growth, on to blood agar slopes. Then the tubes and the subcultures were incubated for a further two days, and the tests were read again. 
The minimal inhibitory concentration of each drug was taken as that concentration which prevented visible growth after five days' incubation at $37^{\circ} \mathrm{C}$. In no case were living gonococci recovered from tubes containing the minimal inhibitory concentration, showing that the action of the drugs on the organisms is bactericidal, and not merely bacteriostatic.

On the evidence of Tables 3 and 4 I consider strains to be resistant if they grow in the presence of a concentration of 1 in 2,500 or more of sulphanilamide, 1 in 40,000 or more of sulphathiazole, 1 in 10,000 or more of sulphadiazine, and 1 in 5,000 or more of sulphapyridine, whereas susceptible strains are inhibited by much lower concentrations of the drugs : this is especially true in the case of sulphathiazole, sulphadiazine and sulphapyridine. It will be seen that, even amongst themselves, the strains showed marked variations and some of the most susceptible in vitro are found amongst the clinically resistant strains $(7,11$ and 20).

Resistance does not run parallel with the clinical findings. Five of the twentyone strains from patients resistant to treatment $(6,7,11,20,21)$ were susceptible in vitro and six of the others $(3,9,14,16,18,19)$ were borderline. Strains $F$ and $H$ and possibly I, which were susceptible in the host, were borderline in vitro. It

TABLE 3-SUSCEPTIBLE STRAINS

Strains susceptible in Host

\begin{tabular}{|c|c|c|c|c|}
\hline \multirow[t]{2}{*}{ STRAIN } & \multicolumn{4}{|c|}{ DRUGS } \\
\hline & $\mathbf{S}$ & ST & SD & $\mathbf{S P}$ \\
\hline A & $\begin{array}{c}1 / 10,000 \\
(0.01)\end{array}$ & $\begin{array}{c}1 / 640,000 \\
(0.000158)\end{array}$ & $\begin{array}{c}1 / 80,000 \\
(0.00125)\end{array}$ & $\begin{array}{l}1 / 160,000 \\
(0.00062)\end{array}$ \\
\hline B & $\begin{array}{c}1 / 5,000 \\
(0 \cdot 2)\end{array}$ & $\begin{array}{r}<1 / 160,000 \\
(0.00062)\end{array}$ & $\begin{array}{l}1 / 80,000 \\
(0 \cdot 00125)\end{array}$ & $\begin{array}{c}1 / 20,000 \\
(0.05)\end{array}$ \\
\hline C & $\begin{array}{c}1 / 5,000 \\
(0.2)\end{array}$ & $\begin{array}{c}<1 / 160,000 \\
(0.00062)\end{array}$ & $\begin{array}{c}1 / 80,000 \\
(0.00125)\end{array}$ & $\begin{array}{l}1 / 20,000 \\
(0.05)\end{array}$ \\
\hline D & $\begin{array}{c}1 / 20,000 \\
(0.005)\end{array}$ & $\begin{array}{c}1 / 10.24 \times 10^{6} \\
(0.0000098)\end{array}$ & $\begin{array}{c}1 / 640,000 \\
(0.000158)\end{array}$ & $\begin{array}{l}1 / 320,000 \\
(0.00031)\end{array}$ \\
\hline E & $\begin{array}{l}1 / 10,000 \\
(0.01)\end{array}$ & $\begin{array}{l}1 / 2.56 \times 10^{8} \\
(0.0000390)\end{array}$ & $\begin{array}{c}1 / 640,000 \\
(0.000158)\end{array}$ & $\begin{array}{l}1 / 320,000 \\
(0.00031)\end{array}$ \\
\hline $\mathbf{F}$ & $\begin{array}{c}1 / 2,500 \\
(0.04)\end{array}$ & $\begin{array}{l}1 / 160,000 \\
(0.00062)\end{array}$ & $\begin{array}{l}1 / 40,000 \\
(0.0025)\end{array}$ & $\begin{array}{l}1 / 40,000 \\
(0.0025)\end{array}$ \\
\hline$G$ & $\begin{array}{c}1 / 5,000 \\
(0.2)\end{array}$ & $\begin{array}{l}1 / 320,000 \\
(0.00031)\end{array}$ & $\begin{array}{l}1 / 80,000 \\
(0.00125)\end{array}$ & \pm \\
\hline H & $\begin{array}{c}1 / 1,250 \\
(0.04)\end{array}$ & $\begin{array}{l}1 / 40,000 \\
(0.0025)\end{array}$ & $\begin{array}{r}1 / 40,000 \\
(0.0025)\end{array}$ & $\begin{array}{l}1 / 40,000 \\
(0.0025)\end{array}$ \\
\hline I & $\begin{array}{c}>1 / 20,000 \\
(0.05)\end{array}$ & $\begin{array}{l}1 / 320,000 \\
(0.00031)\end{array}$ & $\begin{array}{l}>1 / 80,000 \\
(0.00125)\end{array}$ & $\begin{array}{l}>1 / 80,000 \\
(0.00125)\end{array}$ \\
\hline $\mathbf{J}$ & $\begin{array}{l}1 / 160,000 \\
(0.00062)\end{array}$ & $\begin{array}{l}1 / 2.56 \times 10^{6} \\
(0.0000390)\end{array}$ & $\begin{array}{c}1 / 1.28 \times 10^{6} \\
(0.000078)\end{array}$ & $\begin{array}{r}1 / 640,000 \\
(0.000158)\end{array}$ \\
\hline $\mathbf{K}$ & $\begin{array}{c}1 / 10,000 \\
(0.01)\end{array}$ & $\begin{array}{c}1 / 640,000 \\
(0.000155)\end{array}$ & $\begin{array}{c}1 / 640,000 \\
(0.000155)\end{array}$ & $\begin{array}{l}1 / 320,000 \\
(0 \cdot 00031)\end{array}$ \\
\hline $\bar{L}$ & $\begin{array}{c}1 / 2,500 \\
(0.04)\end{array}$ & $\begin{array}{l}1 / 160,000 \\
(0.00062)\end{array}$ & $\begin{array}{c}1 / 20,000 \\
(0.005)\end{array}$ & $\begin{array}{c}>1 / 20,000 \\
(0.005)\end{array}$ \\
\hline
\end{tabular}

The abbreviations used in the above table are similar to those in Table 2 ( $q . v$.)

will be noted that strain 6 was intractable to treatment by sulphanilamide, sulphapyridine, sulphathiazole, sulphadiazine and sulphamezathine, but it was susceptible to their action in vitro. Strains 20 and 21 which were also clinically resistant to three and four drugs respectively were susceptible in vitro to a marked degree.

Cultures of strains 8 and 18 were taken both before the commencement of treatment and after failure with two drugs. In the case of strain 8 the resistance in vitro had become more marked, showing an inherent tendency of the organism 
itself to become drug-fast. In strain 18, however, the behaviour in vitro was not changed significantly by exposure to the drugs in vivo. It would seem, therefore, in this case, that, in the acquisition of drug resistance in vivo, there is some factor other than a change in the organism itself.

TABLE 4-COUPLES INFECTED WITH SAME STRAIN

\begin{tabular}{|c|c|c|c|c|}
\hline \multirow[t]{2}{*}{ STRAIN } & \multicolumn{4}{|c|}{ DRUGS } \\
\hline & $\mathbf{S}$ & ST & SD & SP \\
\hline$(\mathrm{ST}, \mathrm{SD})$ & $\begin{array}{l}1 / 5,000 \\
(0.02)\end{array}$ & $\begin{array}{c}1 / 80,000 \\
(0.00125)\end{array}$ & $\begin{array}{c}1 / 80,000 \\
(0.00125)\end{array}$ & $\begin{array}{l}1 / 160,000 \\
(0.00062)\end{array}$ \\
\hline$(\mathrm{SP}, \mathrm{ST})$ & $\begin{array}{l}1 / 2,500 \\
(0.04)\end{array}$ & $\begin{array}{l}1 / 40,000 \\
(0.0025)\end{array}$ & $\begin{array}{c}1 / 10,000 \\
(0.01)\end{array}$ & $\begin{array}{l}1 / 5,000 \\
(0.02)\end{array}$ \\
\hline $\begin{array}{l}18(1) \\
\text { (ST, SD) } \\
18(2)\end{array}$ & $\begin{array}{c}1 / 20,000 \\
(0.005) \\
1 / 10,000 \\
(0.01)\end{array}$ & $\begin{array}{c}1 / 80,000 \\
(0.00125) \\
1 / 40,000 \\
(0.0025)\end{array}$ & $\begin{array}{r}1 / 40,000 \\
(0.0025) \\
1 / 20,000 \\
(0.005)\end{array}$ & $\begin{array}{l}1 / 40,000 \\
(0.0025 \\
1 / 40,000 \\
(0.0025)\end{array}$ \\
\hline$(\mathrm{ST}, \mathrm{SD}, \mathrm{SM})$ & $\begin{array}{c}1 / 10,000 \\
(0 \cdot 01)\end{array}$ & $\begin{array}{c}1 / 20,000 \\
(0.005)\end{array}$ & $\begin{array}{l}1 / 5,000 \\
(0.02)\end{array}$ & $\begin{array}{l}1 / 40,000 \\
(0.0025)\end{array}$ \\
\hline (ST, $\stackrel{20}{\mathrm{SD}, \mathrm{SP})}$ & $\begin{array}{l}1 / 160,000 \\
(0.00062)\end{array}$ & $\begin{array}{c}1 / 5.12 \times 10^{6} \\
(0.000195)\end{array}$ & $\begin{array}{l}1 / 2.56 \times 10^{6} \\
(0.0000390)\end{array}$ & $\begin{array}{c}1 / 640,000 \\
(0.000155)\end{array}$ \\
\hline $\mathbf{J}$ & $\begin{array}{l}1 / 160,000 \\
(0.00062)\end{array}$ & $\begin{array}{l}1 / 2.56 \times 10^{6} \\
(0.0000390)\end{array}$ & $\begin{array}{c}1 / 1.28 \times 10^{6} \\
(0.000078)\end{array}$ & $\begin{array}{l}1 / 640,000 \\
(0.000158)\end{array}$ \\
\hline
\end{tabular}

The abbreviations used in the above table are similar to those in Table 2 (q.v.).

Strain 10 showed great resistance to drugs in vitro and end points could not be reached owing to the limit of solubility of the drugs.

\section{Treatment}

I do not prescribe urethrovesical irrigations or vaccines as a routine in the treatment of acute gonorrhoea, but as soon as a diagnosis of drug resistance is made, I order irrigations with potassium permanganate, 1 in 7,000 , twice daily and a vaccine every five days. I prefer a stock gonococcal vaccine (not detoxicated) combined with non-specific organisms and comprising : gonococcus, 500 millions per cubic centimetre; staphylococcus, 1,000 millions per cubic centimetre ; diptheroid bacillus, 200 millions per cubic centimetre ; streptococcus, 100 millions per cubic centimetre; bacillus coli, 100 millions per cubic centimetre. The injections are given intramuscularly in the buttock every five days, commencing with 0.2 cubic centimetre and increasing the dose by 0.2 cubic centimetre at each subsequent injection to a maximum of 1 cubic centimetre.

I consider that grande lavage lessens the incidence of complications while the disease is being brought under control, and that the mild protein shock effect of the vaccine may sometimes effect a cure and will often mobilize the defence mechanism so that a further course of chemotherapy, even with the same drug, is sometimes successful. Any beneficial effects following the subcutaneous, intramuscular or intradermal injection of a vaccine are, I am convinced, non-specific and not due to specific active immunization. In many of my cases I give intramuscular injections of 10 cubic centimetres of Aolan (purified casein) twice a week and the results obtained in the treatment of these resistant infections are almost identical. Injections of vaccine or Aolan induce a leucocytosis but are rarely followed by a rise in temperature of more than one degree ; they may also stimulate the formation of non-specific or even specific antibodies.

If gonococci are still present in the urethral secretions after four days of adequate dosage, it is useless to continue with the drug and no improvement follows when moderate dosage is superseded by intensive therapy with the same drug. Satterthwaite, Hill and Huffer report the case of a patient who was resistant to sulphadiazine, 4 grammes daily for five days. The patient was admitted to 
hospital and the daily dosage was increased to 9.6 grammes when a blood level of $11 \cdot 1$ milligrams per cent was obtained but no improvement followed.

Until the introduction of the more active sulphonamides, sulphathiazole and sulphadiazine, changing from one drug to another had no effect when the resistance was complete but sulphapyridine was occasionally successful when the resistance was partial.

After failure with sulphanilamide, sulphacetamide, uleron or sulphapyridine (drugs which I now seldom advise), I find that the giving of sulphathiazole in 4 gramme doses daily for five days effects a cure in 70 per cent of the previously resistant cases. When sulphathiazole fails I change to sulphadiazine (4 grammes daily for five days), a treatment which I have on several occasions found successful in such cases. I have also on three occasions found that sulphamethazine (an inferior sulphonamide in the treatment of gonorrhoea) was successful after sulphathiazole and sulphadiazine had failed, but this may have been due to the time factor.

During the trial period of the various sulphonamides I always persevere with mild non-specific protein shock produced by the vaccine or Aolan. I find this procedure considerably lessens the number of cases requiring more drastic treatment, but when judging the results one must not neglect consideration of the time factor for this may be the cause of some of the successes obtained after mild protein shock has been induced.

When however it is clearly established that an infection fails to react to both chemotherapy and mild protein shock, the induction of general reactions with sharp rise in fever is essential ; but in my opinion fever treatment should not be given until at least three weeks have elapsed after the commencement of chemotherapy. The time factor is as important now as it was in the far-off days of the pre-sulphonamide era when patients who had had no local treatment for two or three months always reacted rapidly to urethrovesical irrigations and surprisingly rapid cures were obtained in a few days. The time factor is significant even when no artificial methods are used to stimulate the patient's resistance and I have

TABLE 5-DIFFERENCE IN DEGREE OF RESISTANCE IN GONOCOCCI Presumed Same Source of Infection : Husband and Wife

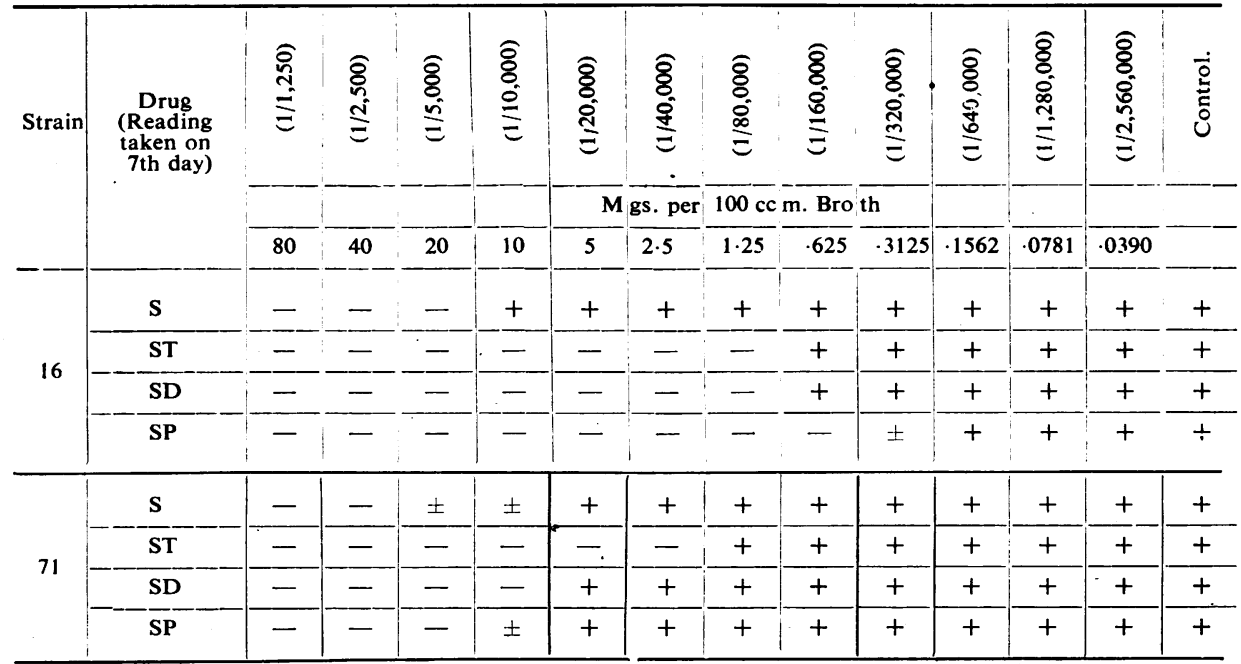

The abbreviations used in the above table are similar to those in Table 2 (q.v.).

never known drug resistance develop in a patient when chemotherapy has been delayed for two months or more after the disease has been contracted.

Systemic fever is induced by physical means (the air-conditioned cabinet, the infra-red cabinet, short-wave diathermy and the high-frequency field) or by intra- 
venous injections of various Gram negative organisms (T.A.B., Dmelcos, and Pyrifer). Fever induced by physical methods, of which I have no experience, has the great advantage of being controlled, but admission to hospital is necessary ; there are dangers and some deaths have been recorded. I prefer the intravenous injection of a vaccine (Harkness, 1940) and am now using T.A.B. vaccine and, as already mentioned, I consider that the results are better when it is delayed until at least three weeks after the disease has been contracted. I do not consider it necessary for the fever to correspond with the thermal death time of the gonococcus since there are often good results when the oral temperature has not been higher than $102^{\circ} \mathrm{F}$. Coupling of the dosage, and the administration of the sulphonamides immediately before the fever session are also unnecessary, the latter in my opinion being definitely harmful. When the sulphonamides fail there is interference with the defence mechanism of the host so why repeat the drug when an effort is being made to stimulate the polymorphonuclear leucocytes and the cells of the reticulo-endothelial system ? Rose, Kendell and Simpson (1941) claim that the combination of chemotherapy and artificial fever therapy is superior to either agent alone and give 7 grammes of sulphathiazole for eighteen hours prior to the administration of fever. It is interesting to note that Trautman (1942) obtained better results with fever alone than with fever combined with chemotherapy in the treatment of gonococcal arthritis.

The first dose of T.A.B. vaccine is $\mathbf{5 0}$ million organisms. After the initial chill (when the patient lies between blankets with a hot water bottle in the bed) the temperature usually begins to rise in one or two hours (but it may be delayed for a longer period) and ranges between $102^{\circ} \mathrm{F}$. and $105^{\circ} \mathrm{F}$., when large quantities of fluids, including 0.6 per cent saline, are given. In some cases there is a secondary rise before the temperature returns to normal. If a good reaction is obtained 75 million organisms are injected on the following day, but if the result is not satisfactory 100 million organisms are given, the injections being repeated as soon as the temperature returns to normal. Permanent cures are often obtained after one injection but in view of the possibility of relapse I often give two injections.

When chemotherapy is unsuccessful fever therapy will often effect a cure, failures in this treatment being more frequent when it is used too early in the disease. It does, however, mobilize the defence mechanism of the body and a further course of chemotherapy, in my experience, has always been successful.

The prostate is always infected in the patients suffering from drug resistance. Massage of this gland is contra-indicated as it may precipitate an acute epididymitis or metastatic complication.

Before administering a further course of chemotherapy in the cases of failure to react to the induction of fever, it is necessary to be particularly careful with the patients who are known to have previously developed a sensitization to one or more of these drugs. In these cases there is usually a history of a widespread eruption with or without drug fever generally occurring after, but rarely before, the seventh day of chemotherapy. Fever therapy is said to desensitize these patients but this has not been my experience with fever associated with the intravenous injection of a vaccine. If the same drug is prescribed alarming symptoms appear often after the first and invariably after the second dose, but in my experience these reactions do not occur after the use of another member of the sulphonamide series. I have known cases in which the patients were sensitive to sulphapyridine and insensitive to sulphanilamide, and others sensitive to sulphadiazine and insensitive to sulphathiazole.

In the treatment of residual lesions, instrumentation and prostatic massage are rarely necessary and on several occasions I have known peri-urethral indurations, well-marked infections of Littré's glands and prostatic swellings to disappear entirely a few days after one fever session.

Unfortunately I have not yet had the opportunity of using penicillin in the treatment of resistant cases, the Penicillin Therapeutic Trials Committee having been unable to cooperate owing to limitation of supplies. Herrell, Cook and Thompson (1943) tested experimentally the antibactericidal activity of penicillin 
on several strains of gonococci cultivated from patients resistant to the sulphonamides. All strains were inhibited in high dilutions. They also treated successfully, by the intravenous drip method, five sulphonamide-resistant cases. Treatment lasted for from three to four days and the dosage of penicillin given to each patient varied between 68,000 and 104,000 Oxford units. Mahoney, Ferguson, Buchholtz and Van Slyke (1943) have issued a preliminary report on the results obtained with the sodium salt of penicillin in the treatment of seventy-four sulphonamideresistant cases and one other case in which the patient had previously shown an acute idiosyncrasy to the sulphonamides. . Ten thousand Florey units in 2 millilitres of distilled water were given intramuscularly at three-hourly intervals for forty-five hours (sixteen injections). Seventy-four of the seventy-five patients responded in a satisfactory manner but there was one therapeutic failure. One patient relapsed eight days after the cessation of treatment and another developed a non-specific epididymitis after fourteen days. Fürther cases (number not stated) suffered from residual urethritis which persisted for eight to ten days but no additional treatment was necessary. The cases have only been observed for eighteen days. It is interesting to note that Pulvertaft (1943) found that penicillin had no effect on Gram negative organisms when it was applied locally to war wounds. If all strains of gonococci are sensitive to penicillin and the host does not develop a tolerance to the drug our troubles are over, but when more of the substance becomes available it will be interesting to know if there are many failures among the sulphonamide-resistant cases.

Before ending my remarks on treatment I would like to emphasize the importance of mild protein shock during the chemotherapy trial period. I have also had excellent results from this method with resistant non-specific urinary infections. I am at present using a combination of the mixed gonococcal vaccine and Aolan (which has been prepared for me by Herts Pharmaceuticals Ltd.) and the results obtained, so far, appear to be better than from either agent alone.

\section{The aetiological factor}

Drug tolerance v. drug fastness.-The clinical investigations of two or more persons infected with the same strain of gonococci give strong evidence in favour of a host factor. Eighty-seven couples were treated and on thirteen occasions one or other was resistant but only twice in both cases. The effects of treatment on the two couples when both parties were resistant to two or more drugs (Cases 16, 17, 18 and 19) showed a marked variation. In Case 17 the mild protein shock effect of a vaccine mobilized the defence mechanism and sulphadiazine effected a cure, whereas in Case 16 it failed and fever therapy followed by a further course of sulphadiazine was necessary. In Case 18 , the patient, after mild protein shock with a vaccine, was cured with sulphamezathine but this drug failed in Case 19 and a further course of mild protein shock with Aolan followed by sulphadiazine was necessary.

Before the introduction of chemotherapy, urethrovesical irrigations, if efficiently carried out, always controlled gonococcal urethritis, but nowadays they fail miserably when the resistance is complete. Local complications are more frequent and even blood-borne infections such as arthritis (which never occurred in the past after the institution of skilled irrigations), although rare, sometimes occur. When the sulphonamides fail in the resistant cases they appear to interfere with the natural resistance of the host. In reviewing the failures in the first series of cases treated with sulphanilamide I noted that all the patients had well-marked glandular involvement and I then considered that this complication was possibly the cause of the resistant infections, but for some time $I$ have been convinced that these glandular infections are merely due to the elimination by the drug of the natural defence mechanism of the host.

The gonococcal fixation reaction on the blood serum registers the presence or absence of specific antibodies; it thus shows the reaction of the host to the invading gonococci. The test was negative in a large number of my resistant cases (this is always so when the resistance is partial) and when it became positive 
further chemotherapy was often successful. Smears of the urethral secretions showed large numbers of the organisms to be extracellular in position and this finding was invariable when the resistance was partial. The above facts possibly indicate that something is lacking in the host.

The methods I adopt in the treatment of this condition aim at stimulating the polymorphonuclear leucocytes and the cells of the reticulo-endothelial system. Each method, including the mild protein shock effect of a vaccine or of Aolan, is followed by a leucocytosis which is at least a contributory factor in overcoming the infection. Another point in favour of a host factor is that, when fever is induced, it is not necessary for the temperature registered to correspond with the thermal death time of the gonococcus.

Most of the laboratory work of other workers on this subject has shown that there is correlation between clinical and in vitro reactions of gonococcal strains. However, the laboratory work carried out for me points definitely to drug tolerance as being a frequent cause of chemotherapy failures. In my second series of twenty-one cases clinically resistant to the sulphonamides; much lower concentrations of the drugs were employed in the in vitro tests than in the first series in which concentrations of 1 in 500 to 1 in 8,000 were employed and the five strains resistant in the host were susceptible in vitro. In this second series five of the strains were susceptible in vitro and six further strains, although possibly susceptible, have been placed in the borderline class as it is admitted that resistant and susceptible types are not always clear-cut entities.

The laboratory investigations concerning the three couples (each presumed to be infected with the same strain) are inconclusive as the number is too small. Strain 20 was resistant to treatment and strain $\mathrm{J}$ was susceptible but both were susceptible in vitro. Strains 16 and 17 (both resistant to treatment) have been placed in the borderline class, the latter being more resistant than the former. Strains 18 and 19 (both resistant to treatment) are also borderline, strain 19 being very slightly more resistant than strain 18 , However, a second specimen taken from strain 18 after failure with two drugs gave results in vitro more nearly approaching those obtained from strain 19 . There remained, nevertheless, a marked difference in the in vitro behaviour of the two strains to sulphadiazine. Table 5 is a typical example of variance within the group and shows an interesting difference in the effect of the four drugs, e.g., strain 16 is susceptible and strain 17 is resistant to sulphapyridine.

\section{ABBREVIATED NOTES OF RESISTANT CASES}

Case 1.-Case of " complete" resistance. Resistant to S. and S.P. No adjuvant treatment. Cured with S.T. G.F.T. negative. Cultures were taken after completion of course of S.

Case 2.-Case of "complete" resistance. Resistant to S., S.P. and S.T. Cured with S.D. Two injections of vaccine were given before the course of S.D. G.F.T. + \pm on completion of treatment. Cultures were taken after failure with S.P.

Case 3.-Case of "complete" resistance. Resistant to S. with methylene blue and S.P. Developed an epididymitis during the course of S. Adjuvant treatment consisted of irrigations and vaccines. G.F.T. + . Cured with S.T. Cultures were taken after failure with S.

Case 4.-Case of " partial" resistance. Also suffering from secondary syphilis. Resistant to S., and S. with methylene blue. Was given two injections of Aolan at weekly intervals. Cured with S.P. No local treatment. G.F.T. negative. Cultures were taken after first course of S.

Case 5.-Case of "complete" resistance. Resistant to S., S.P. and S.T. Vaccines were given throughout and this mild protein shock mobilized the defence mechanism and a further course of S. and methylene blue effected a cure. G.F.T. negative. Cultures were taken before course of S.P.

Case 6.- Case of " complete", resistance. Resistant to S., S.P., S.T., S.D. and S.M. Vaccines given at weekly intervals after failure with $\mathbf{S}$. A profuse urethral discharge persisted throughout treatment. Cured with one intravenous injection of T.A.B. (dosage 50 million organisms). G.F.T. \pm (doubtful). Cultures were taken before commencement of treatment.

Case 7. - Case of " complete" resistance. Resistant to S. Cured with S.T. No local treatment or vaccine. G.F.T. negative. Cultures were taken before commencement of treatment.

Case 8.-Case of " complete" resistance. Resistant to S.M., S.P., S.T. and S.D. Vaccines and urethrovesical irrigations were prescribed after failure with S.M. On completion of course of S.D. large numbers of gonococci (chiefly extracellular in position) were still present in the urethral discharge. An intramuscular injection of 10 cubic centimetres of Aolan produced a 
marked systemic reaction (an unusual occurrence), the oral temperature rising to $103^{\circ} \mathrm{F}$., and when seen a week later the urine was clear. No reactions followed two further injections of Aolan. G.F.T. +. Cultures were taken (1) before commencement of treatment and (2) after failure with S.P.

Case 9.-Case of "complete" resistance. Resistant to S. with methylene blue. Cured with S.T. No local treatment or vaccine. G.F.T. negative. Cultures were taken on completion of course of $S$.

Case 10.-Case of " complete" resistance. Resistant to S.D., S.P. and S. with methylene blue. Vaccines and local treatment were given after failure with S.P. Developed a right epididymitis during the course of S.P. There was a slight rise in temperature after the vaccine injections which were continued for a fortnight after the course of $S$. with methylene blue. The temperature rose to $100^{\circ} \mathrm{F}$. after the last vaccine injection, and when seen a week later there was no discharge and the urine was clear. G.F.T. negative. The mild protein shock of the vaccine effected a permanent cure. Cultures were taken on completion of last course of chemotherapy.

Case 11.-Case of " complete" resistance. Resistant to S. Cured with S.T. Irrigations were given throughout. G.F.T. negative. Cultures were taken on completion of course of S.

Case 12.-Case of " complete" resistance. Resistant to S. and S.P. Cured with S.T. Adjuvant treatment consisted of irrigations only. G.F.T. negative. Cultures were taken during course of S.P.

Case 13.- Case of " complete" resistance. Resistant to S.P. Cured with S.T. No adjuvant treatment. G.F.T. negative. Cultures were taken during course of S.P.

Case 14. - Case of " complete" resistance. Resistant to ten days' course of S.P. Cured with S.T. G.F.T. negative. Cultures were taken before commencement of treatment.

Case 15.-Case of " complete " resistance. Resistant to ten days' course of S. Developed morbilliform eruption. Cured with S.T. (no toxic manifestations). G.F.T. negative. Cultures were taken on completion of course of $\mathbf{S}$.

Case 16.- Case of " complete" resistance. Resistant to S.T. and S.D. Double bartholinitis and salpingitis. Adjuvant treatment consisted of vaccines, sitz baths and vaginal douching with potassium permanganate 1 in 8,000. Two intravenous injections of T.A.B. vaccine (50 and 75 million organisms) failed. Maximal oral temperature on both occasions was $104^{\circ} \mathrm{F}$. A further course of S.D. effected a cure. G.F.T. + \pm . Cultures were taken after failure with S.T.

Case 17.-Case of " complete" resistance. Resistant to S.P. and S.T. Adjuvant treatment consisted of urethrovesical irrigations with potassium permanganate 1 in 8,000 and intramuscular injections of vaccine. The vaccine mobilized the defence mechanism and a course of S.D. cured the gonococcal infection. Irrigations were continued for a further ten days as there was a residual infection due to non-specific organisms. G.F.T. ++ . Cultures were taken after failure with S.T.

Case 18.-Case of " partial " drug resistance. Resistant to S.T. and S.D. Intramuscular injections of vaccine (gonococcus plus secondary organisms) given every five days after failure with S.T. Cured with S.M. G.F.T. negative. Cultures taken (1) before commencement of treatment and (2) after failure with S.T. and S.D.

Case 19.-Case of "partial" drug resistance in the wife" of Case 18, who was five months pregnant. Resistant to S.T., S.D. and S.M. Vaccines and vaginal douching with 1 in 8,000 potassium permanganate during chemotherapy trial period. Gonococci persisted even after three 10-cubic centimetre injections of Aolan given at three-day intervals. A further course of S.D. effected a cure. G.F.T. negative, and most of the organisms were extracellular in position. Cultures taken before commencement of treatment.

Case 20.-Case of " complete" resistance (same strain as $\mathrm{J}$ which was susceptible in vivo and in vitro). Resistant to S.T., S.D. and S.P. Developed bilateral salpingitis and both tubes were drained. G.F.T. negative. A further course of S.T. effected a cure. Cultures were taken before commencement of treatment.

Case 21.-Case of " complete" resistance. Resistant to S.P., S.T., S.D. and S.M. No mild protein shock was prescribed as I had been promised a supply of penicillin. Unfortunately no penicillin was available and the patient was given one intravenous injection of T.A.B. vaccine (50 million organisms). Two hours later the oral temperature rose to $103^{\circ} \mathrm{F}$., falling to $100^{\circ} \mathrm{F}$. after five hours. Two hours later there was a secondary rise to $105^{\circ} \mathrm{F}$. Gonococcal discharge persisted. The G.F.T. which had been negative became strongly positive after fever, and the organisms which had been chiefly extracellular became intracellular in position. A further course of S.T. effected a cure. Cultures were taken after first course of S.T.

$$
\begin{aligned}
\mathbf{S} & =\text { Sulphanilamide. } \\
\text { SD } & =\text { Sulphadiazine. } \\
\text { SM } & =\text { Sulphamezathine. }
\end{aligned}
$$

ST $=$ Sulphathiazole.

$\mathbf{S P}=$ Sulphapyridine

I am grateful to Dr. G. Brownlee and Miss I. M. Tonkin, B.Sc., who carried out the laboratory investigations at the Wellcome Physiological Research Laboratories. I am also grateful for the help I have received from Dr. Haber, my clinical assistant at St. Peter's Hospital.

\section{REFERENCES}

Akatsu, S., and Noguchi, H. (1917) J. exp. Med., $25,349$.

Armuzzi, G., and Hoffmann, E. (1927) Dtsch. med. Wschr., 53, 51. Beerman, H. (1936) Amer. J. Syph., $20,296$. 
Boak, R. A., Charles, R. L., and Carpenter, C. M. (1939) Trans. Amer. Neisserian Soc., Lancaster, Pa., p. 118.

Cohn, A. (1938) Amer. J. Syph., 22, 1.

- Steer, A., and Seijo, Irma (1942) Amer. J. med. Sci., 203, 276.

Dees, J. E., and Colston, J. A. C. (1937) J. Amer. med. Ass., 108, 1855.

Ehrlich, P. (1907) Berl. klin. Wschr., 44, 310.

Fairbrother, R. W., Aymer, C. A., and Ashton, C. W. (1942) Lancet, 1, 464.

Felke, H. (1938) Klin. Wschr., 17, 13.

- (1939) ibid., 18, 568.

Gay, F. P. (1935) Agents of Disease and Host Resistance, including the Principles of Immunology, Bacteriology, Mycology, Protozoology, Parasitology, and Virus Diseases. Springfield, Iil., and London, p. 34.

Harkness, A. H. (1940) Brit. J. vener. Dis., 16, 211.

- (1941) Med. Pr., 206, 431.

Hawking, F. (1937) J. Pharmacol., 59, 123.

Herrell, W. E., Cook, E. N., and Thompson, L. (1943) J. Amer. med. Ass., 122, 289.

Herrold, R. D. (1938) Trans. Amer. Neisserian Soc., Washington, p. 12.

Joses, M. (1942) Nav. med. Bull., Wash., 40, 113.

King, A. J., and Williams, D. I. (1941) Brit. J. vener. Dis., 17, 202.

Kloeppel, F. W. (1926) Münch. med. Wschr., 73, 1936.

Landy, M., Larkum, N. W., Oswald, E. J., and Streightoff, F. (1943) Science, 97, 265.

Levaditi, C., and Vaisman, A. (1938) C. R. Soc. Biol., 127, 1428.

MacCormac, H. (1935) Proc. R. Soc. Med., 28, 1527.

Maclean, I. H., Rogers, K. B., and Fleming, A. (1939) Lancet, 1, 562.

Mahoney, J. F., Ferguson, C., Buchholtz, M., and Van Slyke, C. J. (1943) Amer. J. Syph., 27, 525 .

Mascall, W. N. (1943) Personal communication.

Netherton, E. W. (1943) Arch. Derm. Syph., N.Y., 48, 122.

Petro, J. (1943) Lancet, 1, 35.

Pulvertaft, R. J. V. (1943) Lancet, $2,341$.

Rose, D. L., Kendell, H. W., and Simpson, W. M. (1941) War Med., 1, 470.

Satterthwaite, R. W., Hill, J. H., and Huffer, V. (1942) Vener. Dis. Inform., 23, 249.

Schmith, K., and Reymann, F. E. (1940) Nord. Med. (Hospitalstid.), 8, 2493.

- (1940) ibid., 8, 2500 .

Stokes, J. H. (1934) Modern Clinical Syphilology. Philadelphia and London, 2nd edition, p. 196.

Stokinger, H. E., Charles, R. C., and Carpenter, C. M. (1942) J. Bact., 44, 261.

Templeton, H. J. (1943) Arch. Derm. Syph., N.Y., 48, 412.

Trautman, J. A. (1942) Vener. Dis. Inform., 23, 51.

Westphal, L., Charles, R. L., and Carpenter, C. M. (1940) Vener. Dis. Inform., 21, 183.

Wezel, H. (1938) Münch. med. Wschr., 85, 1897.

Yorke, W. (1933) Brit. J. vener. Dis., 9, 83.

- Murgatroyd, F., and Hawking, F. (1931) Ann. trop. Med. Parasit., 25, 351.

\section{DISCUSSION}

Brig. T. E. Osmond, the President, said that although he thought it was more effective to wait three weeks before employing pyretotherapy, this delay was inexpedient for gonorrhoeal cases in the Army. It was necessary to resort to this form of treatment for soldiers as soon as drug resistance became evident in order to get them back to duty as soon as possible. Fever produced by vaccine injections gave good results in some cases but brilliant ones had been obtained with the Kettering Hypertherm. He understood from his colleagues in the United States Army that penicillin had been used with success in over 90 per cent of drug-resistant gonococcal infections.

Dr. H. M. Hanschell said that an innate resistance of the gonococcus to the sulphonamides was a rare characteristic.: The careful clinical and bacteriological observations made by Dr. Harkness had shown that some factor in the host played a part in the resistance of the infection. Although there was as yet no supporting experimental evidence, the suggestion that the sulphonamides might prevent the development of immune antibodies was an important one. The metabolites which were rendered unusable by the gonococcus were also needed by the tissue cells but presumably their utilization by these tissue cells was also hindered. Although nearly all the early cases of gonococcal infection responded promptly to treatment there were occasional failures. Clinical experience of the failures had shown that after omission of the sulphonamide treatment for a period of five or six weeks, the same dosage of the sulphonamide was often rapidly successful. Presumably antibody formation had been delayed until, at last, it became present in sufficient quantity to provide effective support to the sulphonamide treatment. When considered from the public health aspect evidently it was unwise to use the beneficial effect of this time factor for ambulant patients who were carrying a contagious disease; there should not be any delay in the employment of the sulphonamide drugs. The late Prof. Yorke and his colleagues had shown, as Dr. Harkness had reminded them, that resistant strains of trypanosomes, unlike the susceptible strains, failed to absorb arșenical compounds. This chemotherapeutic action differed from that 